\title{
Analysis of Dielectric Electro Active Polymer Actuator and its High Voltage Driving Circuits
}

Thummala, Prasanth; Huang, Lina; Zhang, Zhe; Andersen, Michael A. E.

Published in:

Proceedings of the International Power Modulator Symposium and High Voltage Workshop

Link to article, DOI:

10.1109/IPMHVC.2012.6518779

Publication date:

2012

Link back to DTU Orbit

Citation (APA):

Thummala, P., Huang, L., Zhang, Z., \& Andersen, M. A. E. (2012). Analysis of Dielectric Electro Active Polymer Actuator and its High Voltage Driving Circuits. In Proceedings of the International Power Modulator Symposium and High Voltage Workshop IEEE. https://doi.org/10.1109/IPMHVC.2012.6518779

\section{General rights}

Copyright and moral rights for the publications made accessible in the public portal are retained by the authors and/or other copyright owners and it is a condition of accessing publications that users recognise and abide by the legal requirements associated with these rights.

- Users may download and print one copy of any publication from the public portal for the purpose of private study or research.

- You may not further distribute the material or use it for any profit-making activity or commercial gain

- You may freely distribute the URL identifying the publication in the public portal 


\title{
Analysis of Dielectric Electro Active Polymer Actuator and its High Voltage Driving Circuits
}

\author{
Prasanth Thummala, Lina Huang, Zhe Zhang and Michael A. E. Andersen \\ Technical University of Denmark, Department of Electrical Engineering, DK-2800 Kongens Lyngby, Denmark \\ Email: $\{$ pthu, huang, zz, ma $\} @$ elektro.dtu.dk
}

\begin{abstract}
Actuators based on dielectric elastomers have promising applications in artificial muscles, space robotics, mechatronics, micro-air vehicles, pneumatic and electric automation technology, heating valves, loud speakers, tissue engineering, surgical tools, wind turbine flaps, toys, rotary motors, and grippers for material handling, etc. This paper focuses on the application of Dielectric Electro Active Polymer (DEAP) technology as an actuation mechanism for different applications. The DEAP material requires very high voltage ( $2.5 \mathrm{kV}$ DC) to fully utilize it as an actuator. In this paper the DEAP actuator is analyzed in detail and the actuator structures, for the wind turbine flap and the heating valve applications are shown. Different high voltage switch mode power supply topologies for driving the DEAP actuator are discussed. The simulation and experimental results are discussed.

Index Terms - Dielectric electro active polymer (DEAP), actuator, high voltage (HV), dc-dc converter, power electronics, heating valves, wind turbine flaps, PolyPower
\end{abstract}

\section{INTRODUCTION}

Smart materials which respond to external stimuli like light, temperature, pressure, $\mathrm{pH}$, magnetic and electric fields by changing their shape or size have been a particular focus in the past decade [1]. The intelligent materials include, shape memory alloys, piezoelectric materials, etc. and deforming active polymers include hydro gels, dielectric elastomers, carbon-nano tubes and liquid crystalline elastomers. Electro Active Polymers (EAPs) that undergoes force and deformation when electrically stimulated were strongly focused in the last years.

An actuator is a mechanical device for moving or controlling a mechanism or a system. EAPs can be used as actuators in active structures, in particular when large deformations are required. Such EAP actuators convert electrical energy into mechanical energy and produce large strains. Several applications of dielectric elastomer actuators were discussed in [2]. From the electrical standpoint, DEAP actuators are capacitive loads. In [3] a low voltage driven DEAP actuator was developed using piezoelectric transformer. A novel activation strategy for dielectric elastomer actuators was proposed in [4]. Section 2 discusses the detailed analysis of the DEAP actuator and its electrical, mechanical, and electromechanical modeling, and the actuator structures for the heating valves and wind turbine flaps applications. We discuss the high voltage DC-DC converter topologies in Section 3, followed by the conclusion in Section 4 .

\section{DIELECTRIC ELASTOMERS AS ACTUATORS}

Electro Active Polymers (EAPs) are categorized into two major classes: ionic and electronic. An electric field or coulomb forces drive electronic EAPs, while the actuation mechanism for ionic EAPs is through the diffusion or mobility of ions. The electronic EAPs generally require high electric fields $(>100 \mathrm{~V} / \mu \mathrm{m})$ and the ionic EAPs requires low driving voltages, nearly equal to $1-5 \mathrm{~V}$. Typical driving voltages for dielectric elastomer actuators lie in the range between $2 \mathrm{kV}$ and $4 \mathrm{kV}$, depending on the polymer breakdown field and thickness of the polymer film. The operating principle of a dielectric elastomer actuator is shown in Figure 1. The DEAP material is a very thin $(\sim 40 \mu \mathrm{m})$ incompressible elastomer film with a compliant electrode layer on both sides [5]. A dielectric elastomer is basically a compliant capacitor. The electrodes are designed to be able to comply with the deformations of the elastomer. As for any capacitor, when an electric field is applied to the electrodes, positive charges appear on one electrode, and negative charges on the other. This gives rise to coulomb forces between opposite charges, generating a pressure, known as the Maxwell stress. The Maxwell stress forces the electrodes to move closer, thereby squeezing the polymer. As the polymer is thinned, it elongates in the directions perpendicular to the applied force [6]. The electro static pressure (or stress) $\sigma$ generated by the actuator is

$\sigma=\varepsilon_{o} \varepsilon_{r}\left(\frac{v_{D E A P}}{x}\right)^{2}=\varepsilon_{o} \varepsilon_{r} E^{2}$

where $E$ is the imposed electrical field, $x$ is the final thickness, $v_{D E A P}$ is the voltage across the DEAP material, and $\varepsilon_{\mathrm{o}}$ and $\varepsilon_{\mathrm{r}}$ are the permittivity of the free space $\left(8.85 \times 10^{-12} \mathrm{~F} / \mathrm{m}\right)$ and the relative permittivity of the polymer, respectively. The mechanical strain $S$ of the DE is given by

$S=-\frac{\varepsilon_{o} \varepsilon_{r}}{Y}\left(\frac{v_{D E A P}}{x_{o} /(1+S)}\right)^{2}=-\frac{\varepsilon_{o} \varepsilon_{r}}{Y}\left(\frac{v_{D E A P}(1+S)}{x_{o}}\right)^{2}$ 
where $Y$ is the Young's modulus and $d_{o}$ is the initial thickness of the material. Using the capacitive behavior of the polymer, DEAP can be used as an actuator, mechano-electrical sensor, as well as energy harvester to generate electricity. When operated as an actuator DEAP show unique properties, such as very low electrical power consumption, high specific elastic energy density, high speed of response, no noise, flexibility, high power density, large bandwidth, higher performance than competing technologies and light weight, hence it has the potential to be an effective replacement for conventional actuators.


Figure 1. Schematic showing the principle of operation of DEAP actuator. Right: Voltage is ON; Left: Voltage is OFF;

\subsection{POLYPOWER DEAP ACTUATOR}

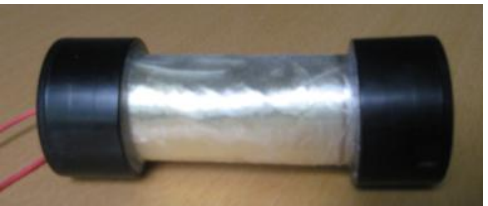

Figure 2. PolyPower DE tubular actuator

PolyPower $^{\mathrm{TM}}$ dielectric elastomer (DE) is a silicone DE manufactured by Danfoss PolyPower A/S, Denmark. PolyPower DEAP actuator (Figure 2) is produced in thin sheets of $40 \mu \mathrm{m}$ thickness. Table 1 shows the properties of the Danfoss PolyPower DEAP material. A DE sheet can be modeled as a strain dependent variable plate capacitor (3). For the unidirectional actuation shown in Figure 3, the capacitance of the DEAP actuator as a function of strain $S$ is

$C=\varepsilon_{o} \varepsilon_{r} \frac{A}{x}=\varepsilon_{o} \varepsilon_{r} \frac{A_{o}(1+S)}{x_{o} /(1+S)}=\varepsilon_{o} \varepsilon_{r} \frac{A_{o}}{x_{o}}(1+S)^{2}$

Table 1. Material properties of Danfoss PolyPower DEAP material

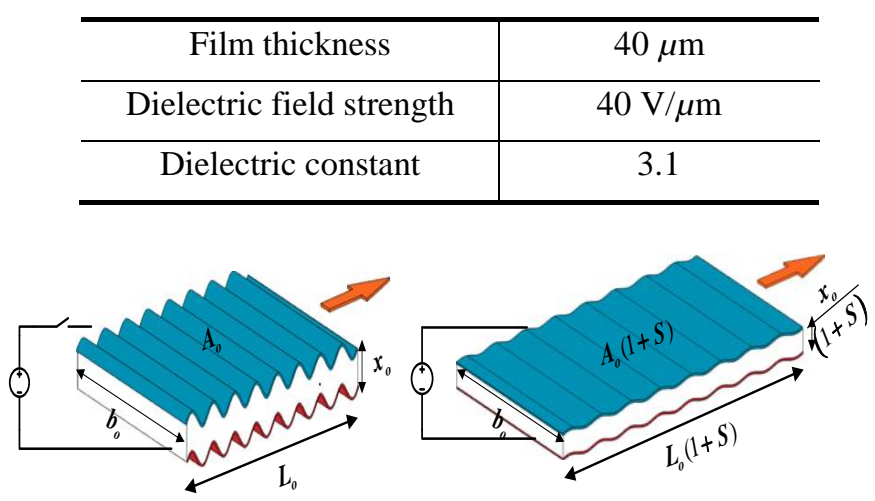

Figure 3. Left: A laminate of PolyPower DE material with corrugated surface and electrode, Right: Actuation direction of the DE material.

\subsection{DEAP ELECTRICAL MODELLING}

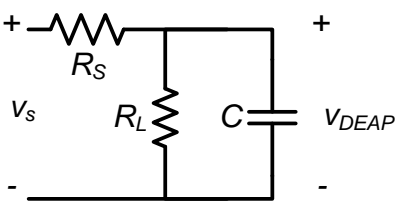

Figure 4a. Electric-circuit model of DEAP actuator

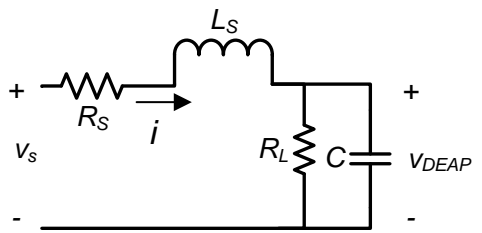

Figure 4b. Electric-circuit model of DEAP actuator including the inductance of the high voltage cables and the compliant electrodes

Figures $4 \mathrm{a}$ and $4 \mathrm{~b}$ show the circuit representation of the electrical model for the DE system employed in this paper. In the figures, $R_{S}$ is the resistance of the electrodes and the wiring, $R_{L}$ is the resistance of the DE material, $C$ is the capacitance of the DE sheet, $L_{S}$ is the equivalent inductance of the electrodes and the high voltage cables, $v_{s}$ is the voltage of the power source, and $v_{D E A P}$ is the voltage over the DE sheet.

For the circuit shown in Figure 4a, the quasi-electrostatic pressure (1) at the surface of the DE sheet is induced by $v_{D E A P}$, which is given by

$\frac{d v_{D E A P}(t)}{d t}+\left(\frac{R_{L}+R_{S}}{R_{L} R_{S} C}\right) v_{D E A P}(t)=\left(\frac{1}{R_{S} C}\right) v_{s}(t)$

Similarly for the circuit shown in Figure $4 \mathrm{~b}$, the differential equations are given as,

$$
\begin{aligned}
& v_{s}(t)=R_{S} i+L_{S} \frac{d i}{d t}+v_{D E A P}(t) \\
& i=\frac{v_{D E A P}(t)}{R_{L}}+C \frac{d v_{D E A P}(t)}{d t}
\end{aligned}
$$

Figures $5 \mathrm{a}$ and $5 \mathrm{~b}$ are the block diagram representations for the electrical equivalents of the DEAP actuator.

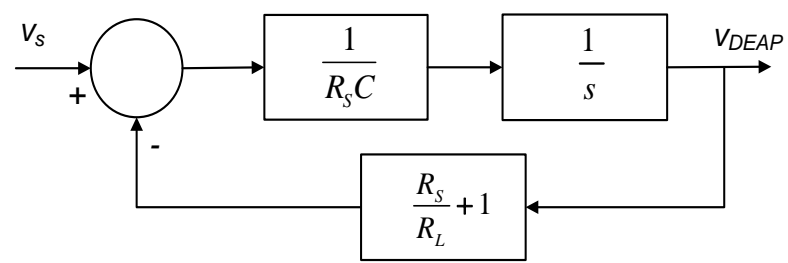

Figure 5a. Block diagram for the electrical circuit of the EAP actuator shown in Figure 4a

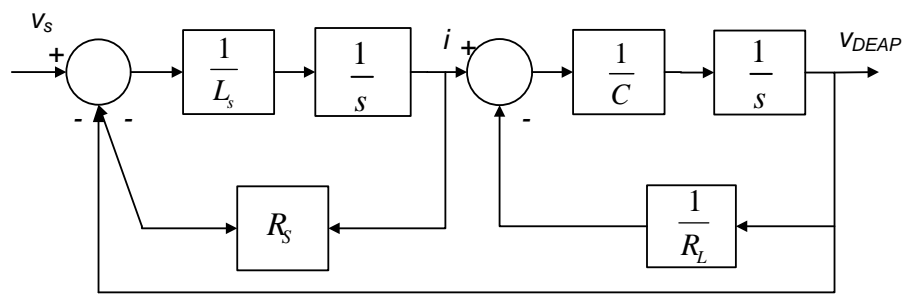

Figure 5b. State block diagram for the electrical circuit of the EAP actuator shown in Figure 4b 


\subsection{DEAP MECHANICAL MODELLING}



Figure 6. Voigt-Kelvin's viscoelastic model with inertial force.

Dielectric polymers exhibit both elastic solid and viscous fluid characteristics. The viscoelastic behavior of the polymers can be modeled as linear elastic spring $\left(E_{0}, E_{1}\right.$ and $\left.E_{2}\right)$ and dashpot networks $\left(\eta_{1}\right.$ and $\left.\eta_{2}\right)$. The viscoelastic behavior of the DE actuators can be predicted by a Voigt-Kelvin fiveparameter model (Figure 6) [7]. The strain response $S(t)$ to a step-stress input $\sigma$ of the five-parameter Voigt-Kelvin model is

$S(t)=\sigma\left(\frac{1}{E_{o}}+\sum_{n=1}^{2} \frac{1}{E_{n}}\left(1-\exp \left(-\frac{t}{\tau_{n}}\right)\right)\right)$

where $\tau_{n}=\eta_{n} / E_{n}$ are the retardation time constants.

\subsection{DEAP ELECTRO-MECHANICAL MODELLING}

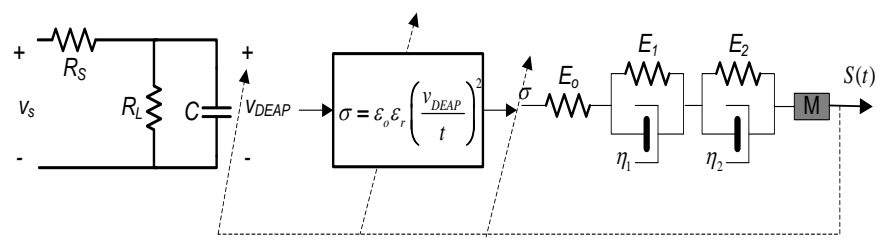

Figure 7. Electro-mechanical modeling of DEAP actuator

Figure 7 shows the electro-mechanical model of DEAP actuator. The input voltage $v_{s}$ generate a voltage across the DEAP capacitor $v_{D E A P}$, which induces an electrostatic pressure $\sigma$. The mechanical part input viz., the electrostatic pressure $\sigma$ is the input that results in a mechanical strain $S$. If the actuation strain $S$ is large, it changes the capacitance $C$, thickness $t$, and the stiffness of the material

\subsection{DIFFERENT STRUCTURES OF DEAP ACTUATORS}

In this paper we focus on the application of DEAP actuator technology to two challenging applications, viz., heating valves and wind turbine flaps. The actuator structures for the two applications are discussed below.

\subsubsection{WIND TURBINE FLAP APPLICATION}
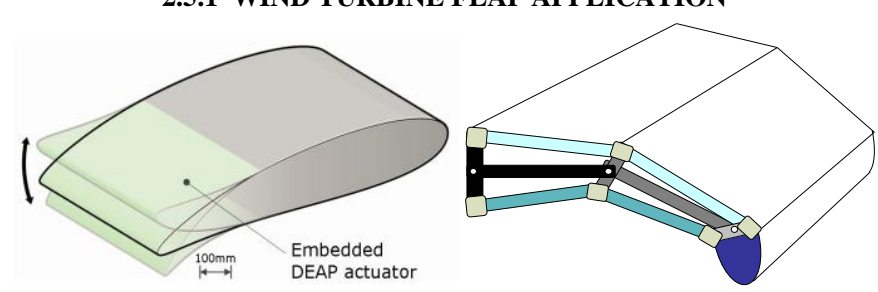

Figure 8. Left: Embedded DEAP actuator into the wing flap; Right: actuated flap structure with DEAP actuators.

Implementing DEAP actuator in the wind turbine flaps will result in improved blade efficiency, reduced loads and fatigues on the blades and turbine. Figure 8 shows the typical structure of the wind turbine flap with embedded DEAP actuators.

\subsubsection{HEATING VALVE APPLICATION}

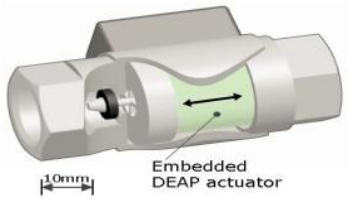

Figure 9. The heating valve containing the DEAP actuator

The current heating valve actuators in the market are thermal actuators, being noiseless but consuming significant power, and electrical gear motors which are relatively energy efficient, but inherently prone to noise issues. The compact inline heating valves based on DEAP actuator will make better, cheaper and noiseless valves without mechanical parts.

\section{HIGH VOLTAGE POWER CONVERTERS TO DRIVE THE DEAP ACTUATOR}

To drive the DEAP actuator a high voltage in the range of kilovolts is required $[3,4]$. For the systematic control of the DEAP actuators that are implemented in a specific application, special high voltage power electronic (HVPE) converters with advanced control techniques are required. Simulation and experimental results for a unidirectional flyback converter are shown.

\subsection{DIFFERENT TOPOLOGIES}

Flyback and full bridge converters shown in Figures 10a and $10 \mathrm{~b}$, are some of the suitable DC-DC converter topologies for high voltage applications. However, the choice of the converter topology depends on the specific requirements of the application, which are shown in Table 2.

Table 2. Specifications of the applications and choice of converter topology

\begin{tabular}{c|c|c}
\hline Application & Input voltage & $\begin{array}{c}\text { Charging Time } \\
\text { of Actuator }\end{array}$ \\
\hline \multirow{2}{*}{$\begin{array}{c}\text { Wind turbine } \\
\text { flap }\end{array}$} & $24 \mathrm{~V}$ (from battery) & $50-100 \mathrm{~ms}$ \\
\cline { 2 - 3 } & $\begin{array}{c}400 \mathrm{~V} \\
\text { (from wind turbine) }\end{array}$ & $5-10 \mathrm{~min}$ \\
\hline Heating valve & $3 \mathrm{~V}$ (from battery) & \multicolumn{2}{|c}{} \\
\hline
\end{tabular}

Table 3. Parameters of the flyback converter used in the experiment

\begin{tabular}{c|c}
\hline Parameters & Values \\
\hline Rated input voltage & $24 \mathrm{~V}$ \\
\hline Rated output voltage & $2.5 \mathrm{kV}$ \\
\hline Magnetizing inductance $L_{p}$ & $35 \mu \mathrm{H}$ \\
\hline Flyback transformer core & $\mathrm{EF} 20, \mathrm{~N} 87$ \\
\hline Primary turns/ Turns ratio & $10 / 20$ \\
\hline Leakage inductance $L_{l k}$ & $800 \mathrm{nH}$ \\
\hline Capacitance of DEAP actuator & $145 \mathrm{nF}$ \\
\hline Primary peak current & $5.3 \mathrm{~A}$ \\
\hline
\end{tabular}




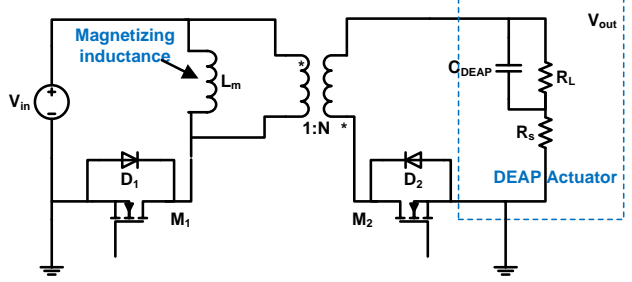

Figure 10a. Schematic of bi-directional flyback converter

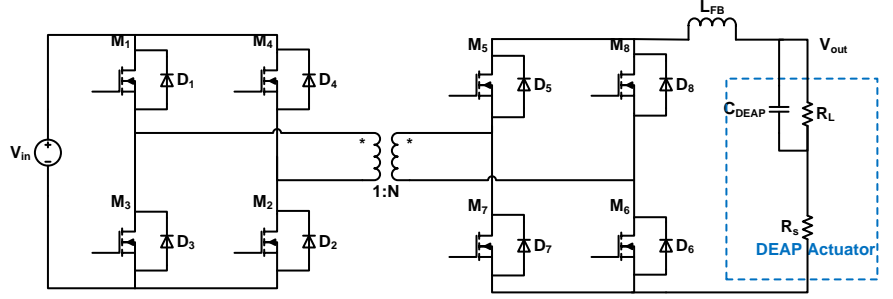

Figure 10b. Schematic of isolated bi-directional full bridge converter.

In this paper we focus only on the flyback topology, for both applications. We used LT3751 capacitor charger controller to generate high voltage. However, for wind turbine flap application, if the output power requirement is too high, isolated full bridge converter is the good choice.

\subsection{SIMULATION AND EXPERIMENTAL RESULTS}

The simulation has been done using LTSpice software. The simulation results for a uni-directional flyback are shown below for different input voltages $\left(V_{i n}=3 \mathrm{~V}, 24 \mathrm{~V}\right.$ and $\left.400 \mathrm{~V}\right)$.

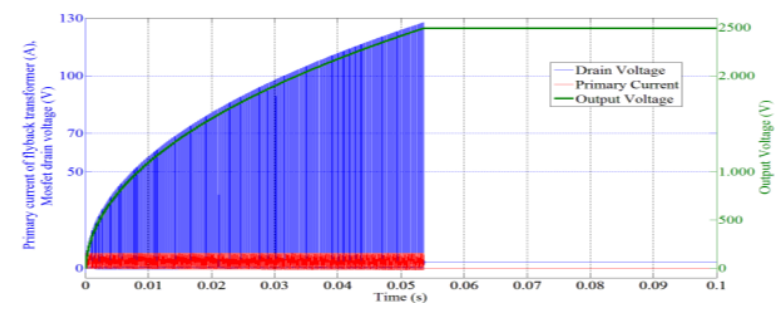

Figure 11. Simulation results of flyback converter for $V_{\text {in }}=3 \mathrm{~V}$

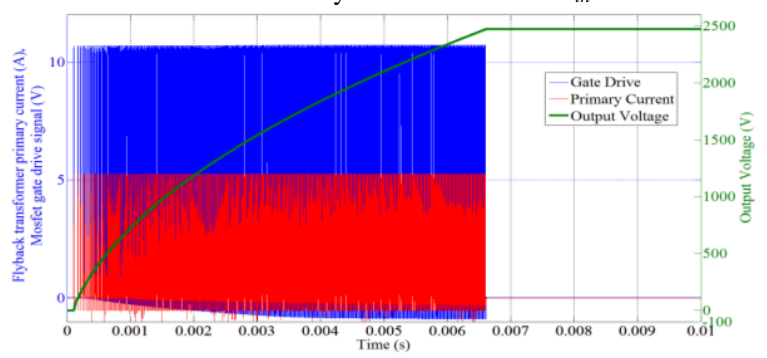

Figure 12. Simulation results of flyback converter for $V_{\text {in }}=24 \mathrm{~V}$

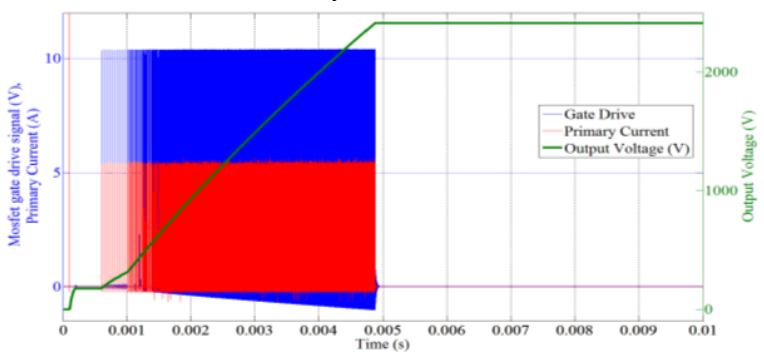

Figure 13. Simulation results of flyback converter for $V_{\text {in }}=400 \mathrm{~V}$

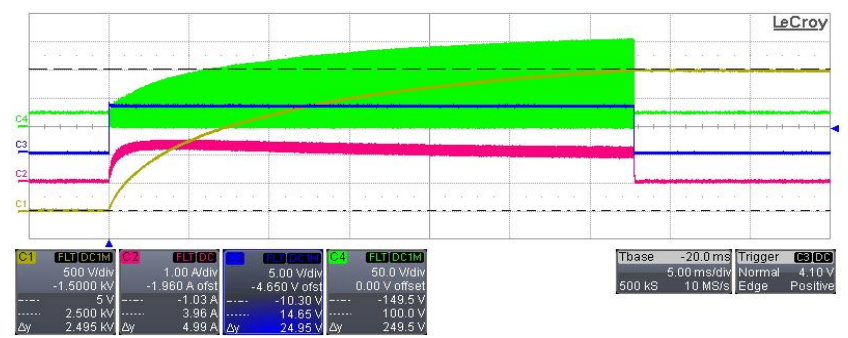

Figure 14. Experimental waveforms (CH1-Output voltage; $\mathrm{CH} 2$-Input current; $\mathrm{CH} 3-\mathrm{Charge}$ signal to the converter; $\mathrm{CH} 4-\mathrm{Mosfet}$ drain voltage)



Figure 15. Experimental waveforms (CH1-Output voltage; $\mathrm{CH} 2$-Primary current; $\mathrm{CH} 3-\mathrm{Charge}$ signal to the converter; $\mathrm{CH} 4-\mathrm{Mosfet}$ gate voltage)

Figures 14 and 15 are the experimental results for the unidirectional flyback converter.

\section{CONCLUSION}

The DEAP actuator is analyzed in detail. And the modeling of the DEAP actuator is presented. Different structures of the DEAP actuators that can be implemented in two different applications are shown. Some high voltage converter topologies for driving the capacitive loads are presented. Finally, simulation and experimental results are shown for a uni-directional flyback converter.

\section{REFERENCES}

[1] Y. Bar-Cohen, Electroactive Polymer (EAP) Actuators as Artificial Muscles: Reality, Potential, and Challenges. SPIE Press, Bellingham, Washington, USA, 2001.

[2] R. Pelrine, P. Sommer-Larsen, R. Kornbluh, R. Heydt, G. Kofod, Q. Pei, P. Gravesen, "Applications of dielectric elastomer actuators", Proc. of SPIE, Smart structures and materials 2001: Electroactive polymer actuators and devices, Vol. 4329, pp. 335-349, 2001.

[3] T. Andersen, M. S. Rødgaard, O. C. Thomsen and M. A. E. Andersen, "Low voltage driven dielectric electro active polymer actuator with integrated piezoelectric transformer based driver," Proceedings of SPIE, vol. 7976, p. 79762N, 2011.

[4] M. Babič, R. Vertechy, G. Berselli, J. Lenarčič, V. Parenti Castelli, G. Vassura, "An electronic driver for improving the open and closed loop electro-mechanical response of Dielectric Elastomer actuators", Mechatronics, Vol. 20, pp. 201-212, 2010.

[5] M. Benslimane, P. Gravesen, P. Sommer-Larsen, "Mechanical properties of dielectric elastomers with smart metallic compliant electrodes", In. Proc. of SPIE Int Soc. Opt. Eng., 4695, pp. 150-157, 2002.

[6] R.E. Pelrine, R.D. Kornbluh, J.P. Joseph, "Electrostriction of polymer dielectrics with compliant electrodes as a means of actuation," Sensors and Actuators, Vol. A 64, pp. 77-85, 1998.

[7] R. Sarban, B. Lassen, M. Willatzen, "Dynamic Electromechanical Modeling of Dielectric Elastomer Actuators With Metallic Electrodes," IEEE/ASME Transactions on Mechatronics, Vol. PP, no.99, pp.1-8, 2011. 